\title{
Obesity and depressive symptoms in mid- life: a population-based cohort study
}

\author{
Anwar Mulugeta ${ }^{1,2^{*}} \mathbb{D}$, Ang Zhou ${ }^{1}$, Christine Power $^{3}$ and Elina Hyppönen ${ }^{1,3}$
}

\begin{abstract}
Background: Obesity and depression are both highly prevalent public health disorders and evidence on their relationship is inconsistent. This study examined whether depressive symptoms are associated with current obesity, and further, whether obesity in turn is associated with an increased odds of depressive symptoms five years later after accounting for potential lifestyle confounders and depressive symptoms at baseline.

Methods: Data were obtained from the 1958 British birth cohort ( $N=9217$ for cross-sectional and 7340 for prospective analysis). Clinical Interview Schedule-Revised and Mental Health Inventory-5 were used for screening depressive symptoms at ages 45 and 50 years, respectively. General and central obesity were defined using measurements of body mass index (BMI) and waist circumference (WC) at 45 years, respectively.

Results: There was a cross-sectional association between depressive symptoms and obesity: participants with $\geq 2$ depressive symptoms had 31\% (95\%Cl 11\% to 55\%) higher odds of general and $26 \%$ higher odds of central obesity (95\% Cl $8 \%$ to $47 \%)$. In prospective analyses, both general and central obesity were associated with higher odds of depressive symptoms five years later among women but not in men ( $P_{\text {interaction }}<0.01$ ). After adjustment for depressive symptoms at baseline, sociodemographic and lifestyle factors, women with general obesity had 38\% (95\% Cl 7\% to $77 \%)$ and women with central obesity 34\% (95\%Cl 9\% to 65\%) higher odds of depression compared to others.

Conclusions: Depressive symptoms are associated with concurrent obesity and related lifestyle factors among women and men in mid-life. Our study suggests that obesity in turn affects long-term risk of depressive symptoms in women but not in men, independently of concurrent associations, providing an important target group for the implementation of preventative strategies.
\end{abstract}

Keywords: General obesity, Central obesity, Depressive symptoms, Middle-age

\section{Background}

Obesity and depression are both highly prevalent public health disorders that affect many age groups and communities [1, 2]. Globally, more than 600 million people are living with obesity while depression affects over 350 million people $[1,3]$. Obesity and depression are interrelated; both are known risk factors for cardiovascular disorders and diabetes [4-6], and relate to negative health and lifestyles factors such as disturbed sleep patterns, sedentary behaviours and dysregulation in appetite and

\footnotetext{
* Correspondence: anwar.mulugeta@aau.edu.et;

gebam006@mymail.unisa.edu.au

'Australian Centre for Precision Health, University of South Australia Cancer

Research Institute, GPO Box 2471, Adelaide, SA 5001, Australia

${ }^{2}$ Department of Pharmacology, School of Medicine, College of Health

Science, Addis Ababa University, Addis Ababa, Ethiopia

Full list of author information is available at the end of the article
}

food intake [7]. These interrelations are clearly complex as use of antidepressant medication often leads to weight gain, as suggested from a review of ten clinical studies that explored the effect of antidepressants on body weight [8]. Furthermore, as evidenced by clinical trials conducted on women [9], dietary restriction targeting weight reduction in obesity may in turn exacerbate depression.

Previous observational studies on the association between obesity and depressive symptoms have provided mixed findings [10-17], with some suggesting a positive association [10], while others have reported an inverse association (obesity associated with lower risk of depression) [12], no association [13], or a u-shaped association (higher risk of depressive symptoms among underweight and obese individuals) [14]. These inconsistencies can

(c) The Author(s). 2018 Open Access This article is distributed under the terms of the Creative Commons Attribution 4.0 International License (http://creativecommons.org/licenses/by/4.0/), which permits unrestricted use, distribution, and 
arise from differences in population characteristics (for example, ethnicity and age) $[12,15,18]$, residual confounding $[19,20]$, or potentially, differences in measures used to define obesity [21]. For example, a study of 3666 individuals from different ethnic groups in USA suggested an association among White but not Black or Mexican Americans [18]. A meta-analysis of 13 crosssectional obesity-depression association studies (median $n=1215$ ), indicated differences in point estimates and statistical precision based on the number of confounders included in the adjustment [20]. Furthermore, most previous studies consider "general" obesity, as measured by body mass index (BMI) [22, 23], while notably less attention has been paid to potential differences in risk based on body fat distribution. While BMI is widely used, it has well-known limitations and may reflect differences in muscle rather than adipose tissue [21]. Some studies have associated central obesity, as measured by waist circumference (WC) or waist-hip ratio (WHR), with depression risk [24]. Adipose tissue is an active endocrine organ associated with increased inflammatory response which relates to depression [25]. White adipose tissue which accumulates typically around the waist is a source of a range of inflammatory markers, which can pass the brain-blood barrier and thereby affect depression risk [26]. Another possibility is that dysregulation of the hypothalamus-pituitary-adrenal (HPA) axis could increase the accumulation of fat around the abdomen as well as leading to alterations in mood [27], possibly indicating a greater importance of central rather than general obesity with respect to depression risk.

This study used data from a large-scale populationbased cohort to establish whether depressive symptoms in mid-adulthood are associated with concurrent general or central obesity and related lifestyle factors, and further, whether obesity in turn predicts the longer term risk of depressive symptoms after accounting for potential sociodemographic and lifestyle confounders and the presence of depressive symptoms at baseline.

\section{Methods}

\section{Study population}

This study used data from 1958 British birth cohort, which included all born in one week of 1958 in England, Scotland and Wales $(N=17,638)$ with immigrants born the same week included up to age 16 years $(N=920)$ [28]. The cohort has been followed up until adulthood, and this study primarily used data from the biomedical survey conducted at age 45 years (target sample 11,971, data collected for 9377) and from the 50 year follow-up [29].

Participants with complete information on depressive symptoms, general and central obesity at age 45 years were included for cross-sectional analysis $(N=9217)$.
Individuals from the cross-sectional analysis who also had information on depressive symptoms at 50 years $(N$ $=7340$ ) were included in the prospective analysis. The flow diagram for the selection of participants is shown in Fig. 1.

\section{Depressive symptoms}

Depressive symptoms at 45 years were assessed using the Clinical Interview Schedule-Revised (CIS-R) [28]. CIS-R was developed for use by lay interviewers as a screening instrument for 14 common mental disorders including depression [30]. CIS-R has been reported to have an acceptable agreement with the Schedule for Clinical Assessment in Neuropsychiatry (SCAN), a clinical diagnostic tool for depression [31]. In the 1958 cohort, the CIS-R was administered by trained nurses; depressive symptoms were assessed using four questions that reflect symptom occurrence over the past week. These include "In the past week have you been able to enjoy or take an interest in things as much as usual?", "In the past week on how many days have you felt sad, miserable or depressed/unable to enjoy or taken an interest in things?", "Did you feel depressed for more than three hours in any day of the week?", and "In the

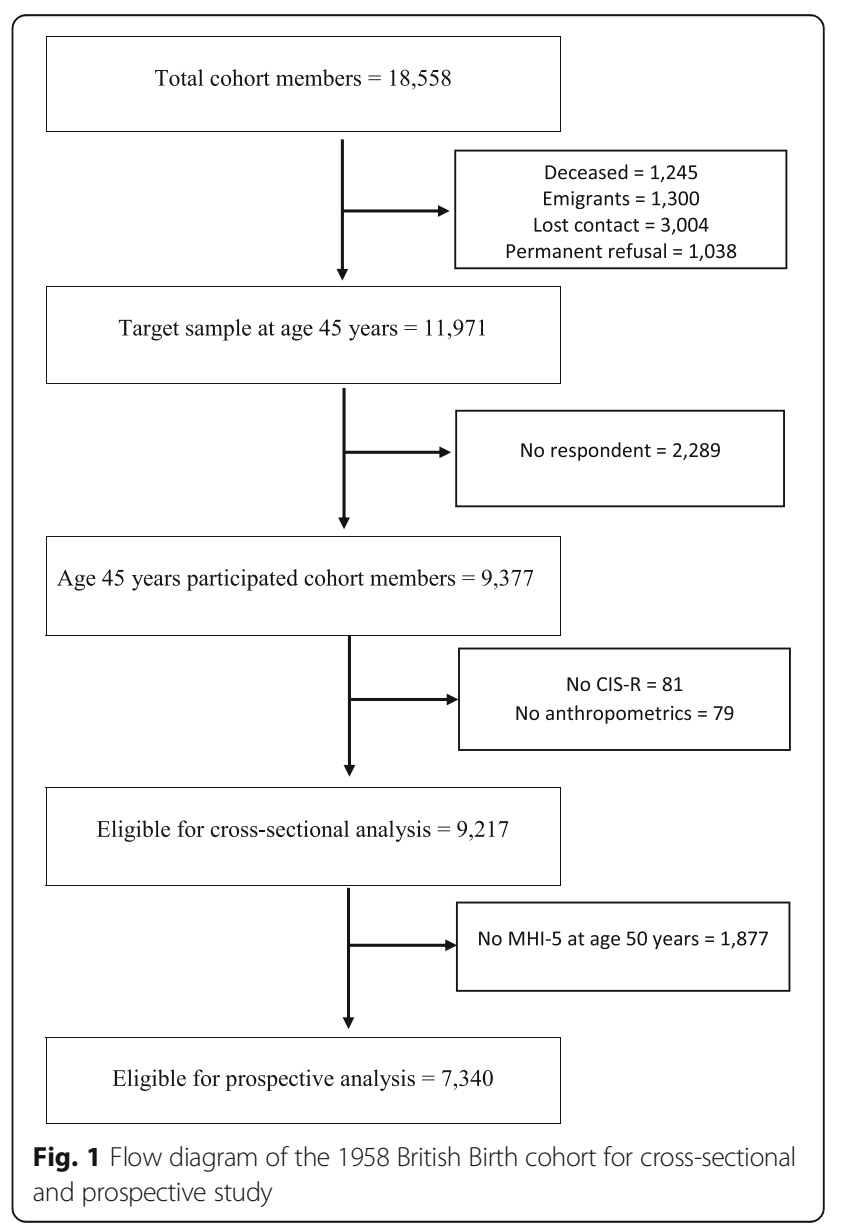


last week during depressive periods, did you feel happier when nice things happened or when you spent time with your friends?". Participants presenting with two or more depressive symptoms were considered as case in our analyses [32, 33].

Mental Health Inventory - 5 (MHI-5), a short version of MHI-38, was used to assess depressive symptoms as part of the postal survey conducted at age 50 years [29] MHI-5 shows an acceptable validity in screening for depression compared to clinical depression diagnostic tools and has an equivalent level of performance in screening depression compared to other screening tools [34, 35]. MHI-5 has five self-administered questions which assess the amount of time in the past four weeks when the participants felt ${ }^{1)}$ happy, ${ }^{2)}$ calm and cheerful ${ }^{3)}$ nervous, ${ }^{4)}$ felt down and low or ${ }^{5)}$ felt like nothing could cheer them up. Each question was rated using six Likert scale options (ranging from none to all of the time) to give a total score range of 5 to 30 [35]. Where needed, scores were converted to have lower values indicating a greater prevalence of symptoms and then scaled to 100. Scores $\leq 52$ were used to indicate clinically significant depressive symptoms [34].

\section{Anthropometric measures}

At age 45 years, height, weight and waist circumference were measured by trained nurses [36]. Weight (in light clothing) was measured with Tanita solar scales, and height (without shoes) with a stadiometer. Using a body tension tape, waist circumference was measured (over light clothing) between the lower ribs and iliac crest in the mid-axillary line [36]. BMI was calculated as weight $(\mathrm{kg})$ over height squared $\left(\mathrm{m}^{2}\right)$. According to WHO classification, BMI was categorized into four groups and coded as underweight $(<18.5)$, normal $(\geq 18.5$ and $<25)$, overweight $(\geq 25$ and $<30)$ and obesity $(\geq 30)$ [37]. Central obesity was defined as waist $W C \geq 102 \mathrm{~cm}$ for males and $\geq 88 \mathrm{~cm}$ for females [38].

\section{Covariates}

Sociodemographic and lifestyle factors were taken from age 45 years or from the nearest possible age sweep where the information was provided. Region of residence at age 45 years was coded as South, Middle and Northern England, London and Scotland; highest educational level attained by 33 years was grouped as $<\mathrm{O}$ level (less than Secondary education), O level, A level or higher (further education) [39]; socioeconomic position at birth (based on father's occupation, or if missing, from age 7 years) and in adulthood (42 years) was categorised using the Registrar General Classification, and coded as I and II (professional/managerial), IIINM (skilled nonmanual), IIIM (skilled manual) and IV and V (partially skilled and unskilled) [40, 41]. Information on smoking (currently non-smoker, ex-smoker or smoker), and physical activity (4-7 times/week, 2-3 times/week, 1 time/ week and $<2-3$ times/month), fruit consumption $(<1$, $1-2$, and $\geq 3$ days/week) were collected at 42 years. Alcohol consumption (non-drinker; light drinker, $<7$ units/ week; moderate drinker, 7-14 units/weeks; heavy drinker, $>14$ units/week), and sedentary behaviour based on time spent viewing a TV or PC ( $\geq 3 \mathrm{~h}$ and $<3 \mathrm{~h} /$ day) were from the 45 year survey.

\section{Statistical analysis}

Logistic regression was used to evaluate both the crosssectional and prospective associations. Cross-sectional analyses of depressive symptoms and obesity (general and central) included adjustments for sex, region, and social class at birth and in adulthood. Prospective analyses of obesity at 45 years and depressive symptoms at 50 years, included adjustments for sex and baseline depressive symptoms (model 1), with further adjustment for sociodemographic factors (region, social class at birth and in adulthood; model 2), and for both sociodemographic, and lifestyle factors (full model, further including alcohol, smoking, sedentary behaviour, physical activity, and fruit consumption; model 3). Models 1 to 3 were repeated for $\mathrm{BMI}$ and WC as continuous variables, using linear regression, to provide trend estimates and to test for curvature (using a quadratic term) of relationships with depression. BMI and WC were analysed separately and also mutually adjusted, to assess their independent effects. Interaction by sex was tested in cross-sectional and prospective analyses, and where found, results are presented separately for men and women.

Information on one or more social or lifestyle covariates was missing for $7 \%$ of cohort members. We used multiple imputation with chained equations (ice command in Stata) and present results from pooled analyses of 15 imputed datasets. There were no notable differences in the effect sizes obtained by analyses using multiple imputation compared to complete case analyses, although associations from models with multiple imputation were typically slightly more precise. All analyses were performed using Stata/ SE 14 software.

\section{Results}

At age 45 years, around a quarter of participants were classified as having general obesity and $35 \%$ with central obesity. The prevalence of depressive symptoms was $8.4 \%$ at 45 years and $12.4 \%$ at 50 years. Sociodemographic and lifestyle factors associated with greater prevalence of general and central obesity were mostly also associated with higher prevalence of depressive symptoms (Table 1 ).

Table 2 shows the cross-sectional associations of depressive symptoms with obesity and lifestyle factors at 
45 years. The odds of obesity were higher for those reporting $\geq 2$ symptoms compared to individuals with no depressive symptoms (OR 1.31, 95\%CI 1.11 to 1.55 and OR $1.26,95 \% \mathrm{CI} 1.08$ to 1.47 , for general and central obesity, respectively). The cross-sectional associations between depressive symptoms and general or central obesity did not vary by sex ( $\left.P_{\text {sex-interaction }}>0.33\right)$. Number of depressive symptoms was also related to sedentary behaviour, smoking and low fruit consumption $(P<$ 0.001 for all comparisons after adjustment for sex, region, social class at birth and in adulthood). The association of depressive symptoms with cigarette smoking and fruit consumption varied by sex $\left(\mathrm{P}_{\text {sex-interaction }}<0.02\right.$ for both comparisons), and both associations were observed in women but not men. Compared to women without symptoms, those with symptoms at baseline had an OR 1.82 (95\% CI 1.38 to 2.19; men OR 1.05, 95\% CI 0.78 to 1.40 ) for smoking and OR 0.51 (95\% CI 0.40 to 0.67 ; men OR $0.76,95 \%$ CI 0.57 to 1.00 ) for fruit consumption.

Both general and central obesity at 45 years were associated with higher odds of depressive symptoms at age 50 years in women but not in men (Table $3, \mathrm{P}_{\text {sex-interac- }}$ tion $<0.01$ for all comparisons). In women, the observed associations between BMI and WC with depressive symptoms were somewhat attenuated by adjustment for sociodemographic and lifestyle factors, but for both obesity indicators the associations remained even after accounting for baseline symptoms, sociodemographic and lifestyle factors (BMI: OR per $10 \mathrm{~kg} / \mathrm{m}^{2} 1.36,95 \% \mathrm{CI}$ 1.15 to 1.62 ; WC: $\mathrm{OR}$ per $5 \mathrm{~cm} 1.07,95 \% \mathrm{CI} 1.03$ to 1.11). In men the fully adjusted OR for BMI was 0.83 $\left(95 \% \mathrm{CI} 0.64\right.$ to $\left.1.10, \mathrm{P}_{\text {trend }}=0.20\right)$ and for $\mathrm{WC} 0.99$ $\left(95 \% \mathrm{CI} 0.94\right.$ to $\left.1.04, \mathrm{P}_{\text {trend }}=0.67\right)$. In a model including all covariates and mutually adjusted for BMI and WC, the association in women for BMI was abolished (OR 0.96, $95 \%$ CI 0.77 to 1.18 ) while the estimate for WC remained significant (OR 1.08, 95\%CI 1.02 to 1.15 ). Again, the corresponding mutually adjusted model among men did not suggest an association either for WC or BMI ( $P>0.16$ for all comparisons).

To further understand the association between obesity and depressive symptoms, we explored the prospective associations between lifestyle factors and depressive symptoms. Alcohol consumption, smoking, sedentary behaviour and fruit consumption were all associated with depressive symptoms at 50 years after adjustment for depressive symptoms at 45 years, sex, sociodemographic and other lifestyle factors (Table 4). The presence of depressive symptoms at age 45 years was associated with an over four-fold greater odds of depressive symptoms at 50 years, attenuating only slightly after adjustment for obesity and lifestyle factors (OR reduced from $4.43(95 \% \mathrm{CI} 3.61$ to 5.43$)$ to 4.11 (95\%CI 3.34 to
5.06)), suggesting further unmeasured influences on the tracking of depressive symptoms.

\section{Discussion}

Tackling the current obesity epidemic both in terms of addressing its causes and consequences remains a key public health priority. Mental wellbeing has broad influences on health and as shown in our large-scale study, the presence of depressive symptoms is strongly associated both with obesity and a broad range of related lifestyle factors. However, as shown in our analyses, even after controlling for these concurrent associations, obesity several years earlier appears to affect subsequent odds of depressive symptoms among women but not in men, providing an important target group for implementation of preventative strategies. Furthermore, this study provided some support for the hypothesis that central rather than general adiposity may have a key role in contributing to the association between obesity and the risk of developing depressive symptoms, highlighting the need of further studies to establish related mechanisms and pathways.

Our work builds on an earlier analysis in the 1958 cohort, which suggested that when looking at categories of BMI from childhood to adulthood (age 7 onwards) obesity was associated with the subsequent odds of depressive symptoms in women but not in men [15]. Inclusion here of central obesity is important because BMI has known weaknesses, especially for men, due to the strong correlation with muscle mass [21]. The result from our previous work [15] is consistent with the current study, and both the analysis using BMI (or general obesity) and WC (or central obesity) suggest that obesity is affecting the likelihood of developing depressive symptoms in women only.

Our findings for higher odds of depressive symptoms by general and central obesity are consistent with several other previous studies [20, 22]. For example, a metaanalysis including eight cross-sectional studies reported the odds of depression to be $35 \%$ higher in people with obesity compared to normal weight individuals [42]. A meta-analysis reporting prospective associations also included eight studies, six of them assessed to be of poor quality by the authors, suggesting an overall $55 \%$ higher odds of depression for those with obesity compared to normal weight, with no evidence for sub-group differences by sex [22]. Another meta-analysis including 15 studies showed $38 \%$ higher odds of depression in individuals with central obesity compared to those without, with higher estimates among women than men [20]. Importantly, unlike these previous studies [20, 22], our study included an adjustment for depressive symptoms at baseline. Furthermore, the weaker effect estimate in our study compared to previous meta-analyses may be 
Table 1 Characteristics and distributions of adult obesity and depressive symptoms by sociodemographic and lifestyle factors

\begin{tabular}{|c|c|c|c|c|c|c|}
\hline Covariates & $\mathrm{N}(\%)$ & $\begin{array}{l}\text { BMl mean } \\
\text { (SD) }\end{array}$ & $\begin{array}{l}\text { General obesity } \\
\mathrm{N}(\%)\end{array}$ & $\begin{array}{l}\text { Central obesity } \\
\mathrm{N}(\%)\end{array}$ & Depression $^{\mathrm{b}}$ age $45 y \mathrm{~N}(\%)$ & Depression $^{c}$ age $50 y \mathrm{~N}(\%)^{d}$ \\
\hline All & 9217 & $27.4(5.0)$ & $2251(24.4)$ & $3208(34.8)$ & $776(8.4)$ & $911(12.4)$ \\
\hline \multicolumn{7}{|l|}{ Gender } \\
\hline Male & $4591(49.8)$ & $27.8(4.3)$ & $1162(25.3)$ & $1503(32.7)$ & $322(7.0)$ & $369(10.5)$ \\
\hline Female & $4626(50.2)$ & $26.9(5.6)$ & $1089(23.5)$ & $1705(36.9)$ & $454(9.8)$ & $542(14.2)$ \\
\hline$P$ & & $<0.001$ & 0.05 & $<0.001$ & $<0.001$ & $<0.001$ \\
\hline \multicolumn{7}{|l|}{ Social class age 42} \\
\hline$|\&| \mid$ & $3715(40.3)$ & $27.2(4.7)$ & $813(21.9)$ & $1188(32.0)$ & $231(6.2)$ & $287(9.4)$ \\
\hline IIINM & $1916(20.8)$ & $26.9(5.0)$ & $419(21.9)$ & $663(34.6)$ & $172(9.0)$ & $222(14.0)$ \\
\hline$\| \mathrm{M}$ & $1711(18.6)$ & $28.1(4.9)$ & $493(28.8)$ & $598(35.0)$ & $127(7.4)$ & $150(11.6)$ \\
\hline IV \& V & $1469(15.9)$ & $27.8(5.5)$ & $423(28.8)$ & $593(40.4)$ & $167(11.4)$ & $183(16.3)$ \\
\hline Others & $406(4.4)$ & $27.7(5.6)$ & $103(25.4)$ & $166(40.9)$ & 79 (19.5) & $69(25.8)$ \\
\hline$p^{a}$ & & $<0.001$ & $<0.001$ & $<0.001$ & $<0.001$ & $<0.001$ \\
\hline \multicolumn{7}{|l|}{ Alcohol (units/week) } \\
\hline Non-drinker & $623(6.8)$ & $28.2(6.3)$ & $193(31.0)$ & $253(40.6)$ & $108(17.3)$ & $114(24.8)$ \\
\hline Light $<7$ & $4476(48.6)$ & $27.6(5.3)$ & $1196(26.9)$ & $1,642(36.7)$ & $367(8.2)$ & $428(11.9)$ \\
\hline Moderate 7-14 & $2226(24.2)$ & $26.8(4.3)$ & $431(19.4)$ & $679(30.5)$ & $137(6.1)$ & $185(10.2)$ \\
\hline Heavy > 14 & 1854(20.0) & $27.3(4.6)$ & $214(21.0)$ & $616(33.2)$ & $160(8.6)$ & $182(12.6)$ \\
\hline Missing & $38(0.4)$ & $27.3(4.6)$ & $10(26.3)$ & $18(47.4)$ & $4(10.5)$ & $2(11.1)$ \\
\hline$p^{a}$ & & $<0.001$ & $<0.001$ & $<0.001$ & 0.002 & 0.008 \\
\hline \multicolumn{7}{|l|}{ Smoking } \\
\hline Never & $4256(46.1)$ & $27.4(5.0)$ & $1024(24.1)$ & $1440(33.8)$ & $307(7.2)$ & $386(10.9)$ \\
\hline Ex-smoker & $2497(27.1)$ & $27.8(5.0)$ & $645(25.8)$ & $914(36.6)$ & $185(7.4)$ & $217(8.7)$ \\
\hline Current smoker & $2161(23.5)$ & $27.0(5.1)$ & $520(24.1)$ & $752(34.8)$ & $249(11.5)$ & $282(13.1)$ \\
\hline Missing & $303(3.3)$ & $27.0(4.7)$ & $62(20.5)$ & $102(33.7)$ & 35 (11.6) & $26(14.1)$ \\
\hline$p^{a}$ & & 0.49 & 0.31 & 0.05 & $<0.001$ & $<0.001$ \\
\hline \multicolumn{7}{|l|}{ Physical activity } \\
\hline$<2-3$ times/month ${ }^{e}$ & $3026(32.8)$ & $28.0(5.5)$ & $878(29.0)$ & $1229(40.6)$ & $317(10.5)$ & $352(14.9)$ \\
\hline 1 time/week & $1670(18.1)$ & $27.4(4.8)$ & $415(24.9)$ & $565(33.8)$ & $104(6.2)$ & $144(10.4)$ \\
\hline 2-3 times/week & $1932(21.0)$ & $27.1(4.5)$ & $413(21.4)$ & $612(31.7)$ & $138(7.1)$ & $161(10.3)$ \\
\hline 4-7 times/week & $2295(24.9)$ & $26.9(4.9)$ & $484(21.1)$ & $703(30.6)$ & $181(7.9)$ & $227(12.2)$ \\
\hline Missing & $294(3.2)$ & $26.9(4.3)$ & $61(20.8)$ & $99(33.7)$ & $36(12.2)$ & $27(15.3)$ \\
\hline$P^{a}$ & & $<0.001$ & $<0.001$ & $<0.001$ & $<0.001$ & 0.003 \\
\hline \multicolumn{7}{|l|}{ Sedentary behaviour } \\
\hline$<3$ h/day & $5806(63.0)$ & $26.9(4.7)$ & 1195 (20.6) & $1751(30.2)$ & $429(7.4)$ & $517(11.0)$ \\
\hline$\geq 3 \mathrm{~h} /$ day & $2995(32.5)$ & $28.4(5.4)$ & $945(31.6)$ & $1296(43.3)$ & $293(9.8)$ & $348(14.9)$ \\
\hline Missing & $416(4.5)$ & $27.7(5.4)$ & $111(26.7)$ & $161(38.7)$ & $54(13.0)$ & $46(16.7)$ \\
\hline$p^{a}$ & & $<0.001$ & $<0.001$ & $<0.001$ & $<0.001$ & $<0.001$ \\
\hline \multicolumn{7}{|l|}{ Fruit consumption } \\
\hline$<1$ day/week & $1676(18.2)$ & $27.5(5.0)$ & $433(25.8)$ & $618(36.9)$ & $195(11.6)$ & $220(17.5)$ \\
\hline 1-2 days/week & $1367(14.8)$ & $27.5(5.1)$ & $349(25.5)$ & $506(37.0)$ & $113(8.3)$ & $161(15.1)$ \\
\hline$\geq 3$ days/week & 5879 (63.8) & $27.4(5.0)$ & 1407 (23.9) & 1984 (33.8) & $432(7.4)$ & $503(10.4)$ \\
\hline Missing & $295(3.2)$ & $27.0(4.3)$ & $62(21.0)$ & $100(33.9)$ & $36(12.2)$ & $27(15.3)$ \\
\hline $\mathrm{P}^{\mathrm{a}}$ & & 0.74 & 0.13 & 0.001 & $<0.001$ & $<0.001$ \\
\hline
\end{tabular}

\footnotetext{
a $P$-value from logistic regression adjusted for sex

${ }^{b}$ Depressive symptoms measured using CIS-R

'Depressive symptoms measured using MHI-5. ${ }^{d}$ Cohort members who had missing data on depressive symptoms at age $50(n=1,877)$ have been excluded. ${ }^{e}$ include individuals who responded no for "Do you do any regular exercise?"
} 
Table 2 Cross-sectional association of depressive symptoms with obesity and lifestyle factors at age 45 years

\begin{tabular}{|c|c|c|c|c|c|c|c|}
\hline \multirow{2}{*}{\multicolumn{2}{|c|}{$N^{c}(\%)$}} & \multicolumn{2}{|c|}{ Obesity, OR $(95 \% \mathrm{Cl})^{\mathrm{a}}$} & \multicolumn{4}{|c|}{ Lifestyle factors ${ }^{\mathrm{b}}, \mathrm{OR}(95 \% \mathrm{Cl})^{\mathrm{a}}$} \\
\hline & & General obesity & Central obesity & Sedentary behaviour & High alcohol consumption & Current smoking & Fruit consumption \\
\hline \multicolumn{8}{|c|}{ Depressive symptoms } \\
\hline None & $7683(83.4)$ & Reference & Reference & Reference & Reference & Reference & Reference \\
\hline 1 & $758(8.2)$ & $1.07(0.90,1.27)$ & $1.02(0.87,1.19)$ & $1.36(1.16,1.59)$ & $1.15(0.95,1.40)$ & $1.47(1.23,1.74)$ & $0.82(0.68,1.00)$ \\
\hline$\geq 2$ & $776(8.4)$ & $1.31(1.11,1.55)$ & $1.26(1.08,1.47)$ & $1.30(1.10,1.53)$ & $1.19(0.99,1.44)$ & $1.53(1.30,1.82)$ & $0.52(0.53,0.76)$ \\
\hline$P_{\text {unadjusted }}$ & & 0.001 & $<0.001$ & $<0.001$ & 0.89 & $<0.001$ & $<0.001$ \\
\hline$P_{\text {adjusted }}{ }^{a}$ & & 0.005 & 0.01 & $<0.001$ & 0.08 & $<0.001$ & $<0.001$ \\
\hline$P_{\text {sex-interaction }}{ }^{d}$ & & 0.33 & 0.58 & 0.52 & 0.11 & $<0.001$ & 0.02 \\
\hline
\end{tabular}

${ }^{\mathrm{a}} \mathrm{P}$-value adjusted and OR $(95 \% \mathrm{Cl})$ : adjustment made for sex, region, social class at birth and social class at age 42 years

${ }^{b}$ Sedentary behaviour, spent 3 or more hrs/day viewing a TV or PC; high alcohol consumption, $>15$ units/week alcohol consumption; current smoking, smoking during age 42 sweep; fruit consumption, $<1$ day/week fruit consumption vs $>1$ day/week fruit consumption

cAll the analysis done in 9217 sample population of the age 45

Interaction between sex and depressive symptoms on obesity and on lifestyle factors after adjustment for sex, region, social class at birth and social class at age 42 years

due to better control for sociodemographic or other confounding factors as most previous studies included in the two meta-analyses [20, 22, 42] were either unadjusted or adjusted for limited set of confounders.

We observed a dose-dependent increase in the odds of depressive symptoms by categories of BMI, which is consistent with most previous studies [10, 13, 43]. However, in some studies, the association between general obesity and depressive symptoms has favoured the "Fat and Jolly" hypothesis, suggesting that obesity may protect against depression [44] while others show a higher odds both for the very thin and obese individuals compared to those with normal weight $[14,16,45]$. It is possible that an increased odds of depression for those who are thin or underweight, can reflect sub-optimal health status [46]. These inconsistencies among studies could be further explained by contextual, and psychosocial influences contributing to the obesity - depression relationship. Individuals who experience stigma and discrimination due to their weight may have low self-esteem and high degree body image dissatisfaction that further aggravate psychological stress and lead to depressive

Table 3 Prospective association between general and central obesity at age 45 years and depressive symptoms at age 50 years $(n=7340)$ among men and women

\begin{tabular}{|c|c|c|c|c|c|c|}
\hline & \multicolumn{3}{|l|}{ Women } & \multicolumn{3}{|l|}{ Men } \\
\hline & $\begin{array}{l}\text { Model-1 } \\
\text { OR (95\% CI) }\end{array}$ & $\begin{array}{l}\text { Model-2 } \\
\text { OR (95\% Cl) }\end{array}$ & $\begin{array}{l}\text { Model-3 } \\
\text { OR (95\% Cl) }\end{array}$ & $\begin{array}{l}\text { Model-1 } \\
\text { OR (95\% Cl) }\end{array}$ & $\begin{array}{l}\text { Model-2 } \\
\text { OR (95\% Cl) }\end{array}$ & $\begin{array}{l}\text { Model-3 } \\
\text { OR (95\% Cl) }\end{array}$ \\
\hline \multicolumn{7}{|l|}{ Body Mass Index } \\
\hline Underweight & $0.72(0.21,2.49)$ & $0.72(0.20,2.50)$ & $0.54(0.15,1.99)$ & $2.47(0.45,13.05)$ & $2.30(0.41,12.80)$ & $1.91(0.33,11.21)$ \\
\hline Normal & Reference & Reference & Reference & Reference & Reference & Reference \\
\hline Overweight & $1.11(0.87,1.40)$ & $1.08(0.85,1.38)$ & $1.10(0.86,1.40)$ & $0.87(0.64,1.13)$ & $0.87(0.65,1.15)$ & $0.86(0.65,1.15)$ \\
\hline Obesity $^{a}$ & $1.56(1.22,1.98)$ & $1.46(1.14,1.86)$ & $1.38(1.07,1.77)$ & $0.87(0.63,1.21)$ & $0.87(0.63,1.21)$ & $0.85(0.61,1.18)$ \\
\hline Per $10 \mathrm{~kg} / \mathrm{m}^{2}$ & $1.48(1.26,1.74)$ & $1.41(1.20,1.67)$ & $1.36(1.15,1.62)$ & $0.87(0.66,1.14)$ & $0.86(0.65,1.12)$ & $0.83(0.64,1.10)$ \\
\hline$P_{\text {trend }}$ & $<0.001$ & $<0.001$ & $<0.001$ & 0.31 & 0.26 & 0.20 \\
\hline$P_{\text {curvature }}$ & 0.25 & 0.19 & 0.32 & 0.05 & 0.11 & 0.14 \\
\hline \multicolumn{7}{|l|}{ Waist circumference } \\
\hline Normal & Reference & Reference & Reference & Reference & Reference & Reference \\
\hline Central obesity $^{\mathrm{b}}$ & $1.48(1.21,1.81)$ & $1.41(1.15,1.73)$ & $1.34(1.09,1.65)$ & $0.97(0.75,1.23)$ & $0.94(0.73,1.21)$ & $0.90(0.70,1.17)$ \\
\hline Per $5 \mathrm{~cm}$ & $1.10(1.06,1.14)$ & $1.09(1.05,1.13)$ & $1.07(1.03,1.11)$ & $1.00(0.95,1.05)$ & $1.00(0.95,1.05)$ & $0.99(0.94,1.04)$ \\
\hline$P_{\text {trend }}$ & $<0.001$ & $<0.001$ & $<0.001$ & 0.99 & 0.88 & 0.67 \\
\hline
\end{tabular}

$\mathrm{P}_{\text {sex-interaction }}$ is the interaction between sex and obesity variables at age 45 years on depression at age 50 years (For all obesity variables, $\mathrm{P}_{\text {sex-interaction }}<0.01$ ) Model-1, adjusted for depressive symptoms at age 45 years; Model-2, adjusted for depressive symptoms at age 45 years, and region, social class at birth and social class at adulthood; Model-3, adjusted for depressive symptoms at age 45 years, region, social class at birth, social class at adulthood, fruit consumption, physical activity, sedentary behaviour, smoking, alcohol) ${ }^{\mathrm{a} B M I} \geq 30 \mathrm{~kg} / \mathrm{m}^{2}$

${ }^{b} W C \geq 102 \mathrm{~cm}$ for men and WC $\geq 88 \mathrm{~cm}$ for women 
Table 4 Lifestyle factors and the risk of depressive symptoms at age 50 years

\begin{tabular}{|c|c|c|c|}
\hline & Adjusted for sex, depressive symptoms at $45 y, \&$ other factors ${ }^{a}$ & Full adjustment $^{b}$ & \\
\hline & $\mathrm{OR}(95 \% \mathrm{Cl})$ & $\mathrm{OR}(95 \% \mathrm{Cl})$ & $P_{\text {sex-interaction }}$ \\
\hline Alcohol & & & 0.40 \\
\hline Non-drinker & $1.98(1.52,2.58)$ & $1.88(1.44,2.46)$ & \\
\hline Light $<7$ units/week & Reference & Reference & \\
\hline Moderate 7-14 units/week & $0.98(0.80,1.19)$ & $1.00(0.82,1.22)$ & \\
\hline Heavy > 14 units/week & $1.23(1.00,1.51)$ & $1.17(0.95,1.45)$ & \\
\hline$P$ & $<0.001$ & $<0.001$ & \\
\hline Smoking & & & 0.05 \\
\hline Never & Reference & Reference & \\
\hline Ex-Smoker & $0.96(0.80,1.16)$ & $0.93(0.77,1.13)$ & \\
\hline Current smoker & $1.51(1.25,1.81)$ & $1.33(1.09,1.61)$ & \\
\hline P & $<0.001$ & 0.003 & \\
\hline Physical activity & & & 0.51 \\
\hline 2-3 times/month & Reference & Reference & \\
\hline 1 time/week & $0.79(0.63,0.98)$ & $0.88(0.71,1.10)$ & \\
\hline 2-3 times/week & $0.76(0.61,0.94)$ & $0.88(0.70,1.09)$ & \\
\hline 4-7 times/week & $0.86(0.71,1.05)$ & $0.98(0.81,1.20)$ & \\
\hline$P$ & 0.04 & 0.52 & \\
\hline Sedentary behaviour & & & 0.09 \\
\hline$<3$ h/day & Reference & Reference & \\
\hline$\geq 3$ h/day & $1.36(1.16,1.59)$ & $1.20(1.02,1.41)$ & \\
\hline$P$ & $<0.001$ & 0.05 & \\
\hline Fruit consumption & & & 0.02 \\
\hline$<1$ day/week & Reference & Reference & \\
\hline 1-2 days/week & $0.93(0.73,1.18)$ & $0.98(0.76,1.25)$ & \\
\hline$\geq 3$ days/week & $0.60(0.49,0.73)$ & $0.67(0.55,0.82)$ & \\
\hline P & $<0.001$ & $<0.001$ & \\
\hline Depressive symptoms at age $45 y$ & & & 0.36 \\
\hline No & Reference & Reference & \\
\hline Yes & $4.43(3.61,5.43)$ & $4.11(3.34,5.0)$ & \\
\hline$P$ & $<0.001$ & $<0.001$ & \\
\hline
\end{tabular}

P-value based on Likelihood ratio test

aSociodemographic factors included region, social class at birth and social class at age 42 years

${ }^{\mathrm{b}}$ Full adjustment involved sex, depressive symptoms at age 45 years, sociodemographic factors, general and central obesity, alcohol, smoking, physical activity, sedentary behaviour, and fruit consumptions

symptoms [47]. Indeed, the possible stigma and discrimination due to excessive body weight is likely to have a greater impact on women than men which may explain the observed gender difference [47].

Mechanisms underlying the association between obesity and depression remains unclear, however, molecular and clinical studies have provided some evidence for the involvement of HPA axis, inflammatory pathways and insulin sensitivity [48], with dysregulation of HPA axis, elevation of certain inflammatory markers and insulin resistance being observed in both individuals with obesity and in individuals with depression
[49-51]. Disturbance in any of these systems may affect the secretion or metabolism of neurotransmitters, such as serotonin, norepinephrine and dopamine, in the brain and consequently influence mood $[48,52]$. Findings regarding inflammatory pathways and insulin sensitivity are particularly interesting: the observed elevated inflammatory markers, including leptin, adiponectin and IL-6 and TNF- $\alpha$ are mainly secreted from white adipose tissue found on the abdomen [26]; abdominal obesity, in particular, places people at higher risk for developing insulin resistance [53]. All these observations resonate with our findings of an independent association for WC and 
highlight the particular importance of central obesity on the risk of developing depressive symptoms.

Our study also suggests that the association between obesity and depressive symptoms is in part related to socioeconomic and lifestyle factors, with obesity associations attenuating by about 30\% after allowing for such factors. This attenuation was expected considering that most studies show lower socioeconomic status and unhealthy lifestyle factors to be associated with obesity and depression $[54,55]$ although some factors may be on the causal pathway from obesity to depressive symptoms. For example, obesity may lead to less active lifestyles as well as inactivity increasing the risk of obesity [56]. Even so, given the links shown here between lifestyle factors and depressive symptoms, our study suggests that these behaviours may be additional targets for interventions to reduce obesity and depression.

\section{Limitations}

It is important to emphasise the following limitations of this study. Firstly, our study used the presence of depressive symptoms as the outcome rather than defining it based on the diagnosis of depressive disorder. In an earlier meta-analysis, the association between obesity and depression was found to be stronger for depressive disorder than for depressive symptoms [22]. This may explain why the associations found here are weaker than other reported estimates. Different instruments were used to assess depressive symptoms at ages 45 and 50 years, although both have been shown to be valid, with similar performance compared to standard diagnostic tools and both have been used in community-based epidemiological studies for screening of depressive symptoms $[57,58]$. Another limitation relates to representativeness, as the ethnic composition of the current UK population is notably more diverse compared to the participants included here, $98 \%$ of whom were European origin [28]. Hence, the results may not be generalisable to today's more ethnically diverse population in the UK. A further limitation relates to inadequately measured or unmeasured confounding: although a broad range of lifestyle and sociodemographic factors were included, some measures (e.g. sedentary behaviour, physical activity) may have limitations, whilst in total the measures may not have captured all variation influencing the association between obesity and depressive symptoms. Finally, our study is limited in its ability to fully dissect independent effects of general and central adiposity. BMI and WC are highly correlated, and while our analyses suggest that WC may be the major influence, further studies avoiding problems with collinearity are needed to confirm this interpretation. Alternative approaches such as Mendelian randomisation may provide further insights into the independent causal roles of central and general obesity on depression risk.

\section{Conclusion}

Depressive symptoms are associated with obesity and related lifestyle factors in mid-life. Our study suggests that obesity affects subsequent risk of developing depressive symptoms among women independently of these concurrent associations, providing an important target group for implementation of preventative strategies. In the management of depressive symptoms, one of the alternative approaches could be targeting and managing obesity and unfavourable lifestyle factors.

\section{Abbreviations}

BMI: Body Mass Index; CIS-R: Clinical Interview Schedule - Revised; HPA: Hypothalamus-Pituitary-Adrenal Axis; IL-6: InterLeukin-6; MHI-5: Mental Health Inventory-5; MHI-8: Mental Health Inventory-8; OR: Odds Ratio;

PC: Personal Computer; SCAN: Schedule for Clinical Assessment in Neuropsychiatry; TNF-a: Tissue Necrotizing Factor-a; TV: Television; UK: United Kingdome; WC: Waist Circumference; WHO: World Health Organisation; WHR: Waist - Hip Ratio

\section{Acknowledgements}

The authors are grateful to the Centre for Longitudinal Studies (CLS), UCL Institute of Education for the use of these data and to the UK Data Service for making them available. However, neither CLS nor the UK Data Service bear any responsibility for the analysis or interpretation of these data. The authors are thankful to Australian Research Training program Scholarship for AM's studentship support.

\section{Funding}

The National Child Developmental study sweep 6 were funded by Economic and Social Council, and Government Departments. Medical Research Council funded the biomedical survey. Chris Power was funded by the Department of Health Policy Research Programme through the Public Health Research Consortium (PHRC) and supported by the National Institute for Health Research Biomedical Research Centre at Great Ormond Street Hospital for Children NHS Foundation Trust and University College London. The views expressed in the publication are those of the authors and not necessarily those of the Department of Health. Information about the wider programme of the PHRC is available from http://phrc.Ishtm.ac.uk. Funding organisation has no role in the study design, analysis, and interpretation of results or writing of the report.

\section{Availability of data and materials}

The data that support the findings of this study are available from Center for Longitudinal Studies but restrictions apply to the availability of these data, which were used under license for the current study, and so are not publicly available. Data are however available from the authors upon reasonable request and with permission of Center for Longitudinal Studies.

\section{Authors' contributions}

EH conceptualised the study. AM, EH and AZ contributed to the planning, data analysis and interpretation. AM drafted the paper. $E H, A Z$ and $C P$ critically revised the paper and all authors approved the final manuscript.

\section{Ethics approval and consent to participate}

Ethical approval for the biomedical survey was given from the South East Multicentre Research Ethics Committees (ref 01/1/44) and for the 2008 (age 50) survey was from London Multicentre Research Ethics Committees; informed consent was obtained from survey participants. 


\section{Competing interests}

The authors declare that they have no competing interests.

\section{Publisher's Note}

Springer Nature remains neutral with regard to jurisdictional claims in published maps and institutional affiliations.

\section{Author details}

'Australian Centre for Precision Health, University of South Australia Cancer Research Institute, GPO Box 2471, Adelaide, SA 5001, Australia. ²Department of Pharmacology, School of Medicine, College of Health Science, Addis Ababa University, Addis Ababa, Ethiopia. ${ }^{3}$ Population, Policy and Practice, UCL Great Ormond Street Institute of Child Health, London, UK.

\section{Received: 15 May 2018 Accepted: 5 September 2018}

\section{Published online: 17 September 2018}

\section{References}

1. Obesity and Overweight [http://www.who.int/mediacentre/factsheets/fs311/ en/]. (accessed 24.11.16)

2. Depression: A Global Public Health Concern [http://www.who.int/mental_ health/management/depression/en/]. (Accessed 4 July 2016)

3. Lopez AD, Murray CJL. The global burden of disease, 1990 - 2020. Nat Med. 1998:4(11):1241-3.

4. Pan A, Lucas M, Sun Q, Van Dam RM, Franco OH, Manson JE, Willett WC, Ascherio A. Hu FB. Bidirectional association between depression and type 2 diabetes mellitus in women. Arch Intern Med. 2010;170(21):1884-91.

5. Lippi G, Montagnana M, Favaloro EJ, Franchini M. Mental depression and cardiovascular disease: a multifaceted, bidirectional association. Semin Thromb Hemost. 2009:35(3):325-36.

6. Casanueva FF, Moreno B, Rodriguez-Azeredo R, Massien C, Conthe P, Formiguera X, Barrios V, Balkau B. Relationship of abdominal obesity with cardiovascular disease, diabetes and hyperlipidaemia in Spain. Clin Endocrinol. 2010;73(1):35-40.

7. Reeves GM, Postolache TT, Snitker S. Childhood obesity and depression: connection between these growing problems in growing children. Int J Child Health Human Dev. 2008:1(2):103-14.

8. Lee SH, Paz-Filho G, Mastronardi C, Licinio J, Wong ML. Is increased antidepressant exposure a contributory factor to the obesity pandemic? Transl Psychiatry. 2016;6:e759.

9. Smith KA, Williams C, Cowen PJ. Impaired regulation of brain serotonin function during dieting in women recovered from depression. $\mathrm{Br} J$ Psychiatry. 2000;176:72-5

10. Herva A, Laitinen J, Miettunen J, Veijola J, Karvonen JT, Laksy K, Joukamaa M. Obesity and depression: results from the longitudinal northern Finland 1966 birth cohort study. Int J Obes. 2006;30(3):520-7.

11. Chaiton M, Sabiston C, O'Loughlin J, McGrath JJ, Maximova K, Lambert M. A structural equation model relating adiposity, psychosocial indicators of body image and depressive symptoms among adolescents. Int J Obes. 2009:33(5):588-96.

12. Li ZB, Ho SY, Chan WM, Ho KS, Li MP, Leung GM, Lam TH. Obesity and depressive symptoms in Chinese elderly. Int J Geriatr Psychiatry. 2004; 19(1):68-74.

13. Van Gool CH, Kempen Gl, Bosma H, van Boxtel MP, Jolles J, van Eijk JT. Associations between lifestyle and depressed mood: Iongitudinal results from the Maastricht aging study. Am J Public Health. 2007;97(5):887-94.

14. de Wit LM, van Straten A, van Herten M, Penninx BW, Cuijpers P. Depression and body mass index, a u-shaped association. BMC Public Health. 2009;9:14.

15. Geoffroy MC, Li L, Power C. Depressive symptoms and body mass index: Comorbidity and direction of association in a British birth cohort followed over 50 years. Psychol Med. 2014:44(12):2641-52.

16. Noh JW, Kwon YD, Park J, Kim J. Body mass index and depressive symptoms in middle aged and older adults. BMC Public Health. 2015;15:310.

17. Kodjebacheva G, Kruger DJ, Rybarczyk G, Cupal S. Racial/ethnic and gender differences in the association between depressive symptoms and higher body mass index. J Public Health. 2015:37(3):419-26.

18. Hicken MT, Lee H, Mezuk B, Kershaw KN, Rafferty J, Jackson JS. Racial and ethnic differences in the association between obesity and depression in women. J Womens Health. 2013;22(5):445-52.

19. Skelly AC, Dettori JR, Brodt ED. Assessing bias: the importance of considering confounding. Evid Based Spine Care J. 2012;3(1):9-12.
20. Xu Q, Anderson D, Lurie-Beck J. The relationship between abdominal obesity and depression in the general population: a systematic review and meta-analysis. Obes Res Clin Pract. 2011;5(4):e267-360.

21. Stevens J, McClain JE, Truesdale KP. Selection of measures in epidemiologic studies of the consequences of obesity. Int J Obes. 2008;32(Suppl 3): S60-6.

22. Luppino FS, de Wit LM, Bouvy PF, Stijnen T, Cuijpers P, Penninx BW, Zitman FG. Overweight, obesity, and depression: a systematic review and meta-analysis of Iongitudinal studies. Arch Gen Psychiatry. 2010; 67(3):220-9.

23. de Wit L, Luppino F, van Straten A, Penninx B, Zitman F, Cuijpers P. Depression and obesity: a meta-analysis of community-based studies. Psychiatry Res. 2010;178(2):230-5.

24. Janssen I, Katzmarzyk P, Ross R. Waist circumference and not body mass index explains obesity-related health risk. Am J Clin Nutr. 2004;79:6.

25. Kershaw EE, Flier JS. Adipose tissue as an endocrine organ. J Clin Endocrinol Metab. 2004:89(6):2548-56.

26. Shelton R, Miller A. Inflammation in depression: is adiposity a cause? Dialogues Clin Neurosci. 2011:13:13.

27. Thakore JH, Richards PJ, Reznek RH, Martin A, Dinan TG. Increased intraabdominal fat deposition in patients with major depressive illness as measured by computed tomography. Biol Psychiatry. 1997;41(11):1140-2.

28. Power C, Elliott J. Cohort profile: 1958 British birth cohort (National Child Development Study). Int J Epidemiol. 2006;35(1):34-41.

29. The 1958 National Child Development Study [http://www.cls.ioe.ac.uk/page. aspx?\&sitesectionid=724\&sitesectiontitle=National+Child+Development +Study]. Accessed 26 July 2016.

30. Lewis G, Pelosi AJ, Araya R, Dunn G. Measuring psychiatric disorder in the community: a standardized assessment for use by lay interviewers. Psychol Med. 1992;22(2):465-86

31. Jordanova V, Wickramesinghe C, Gerada C, Prince M. Validation of two survey diagnostic interviews among primary care attendees: a comparison of CIS-R and CIDI with SCAN ICD-10 diagnostic categories. Psychol Med. 2004:34(6):1013-24.

32. Jenkins $R$, Lewis $G$, Bebbington $P$, Brugha T, Farrell M, Gill B, Meltzer $H$. The National Psychiatric Morbidity surveys of Great Britain--initial findings from the household survey. Psychol Med. 1997;27(4):775-89.

33. Das-Munshi J, Goldberg D, Bebbington PE, Bhugra DK, Brugha TS, Dewey ME, Jenkins R, Stewart R, Prince M. Public health significance of mixed anxiety and depression: beyond current classification. $\mathrm{Br}$ J Psychiatry. 2008;192(3):171-7.

34. Holmes WC. A short, Psychiaatric, case-finding measure for HIV Seropossetive outpatients: performance characterstics of the 5-item mental health subscale of the SF-20 in a male, seroposetive sample. Med Care. 1998:36(2):8.

35. Berwick D, Murphy J, Goldman P, Ware J, Barsky A, Weinstein M. Perfornmance of a five-item mental health screening test. Med Care. 1991;29(2):8.

36. Tehnical report on the national child development study biomedical survey 2002-2004. [www.cls.ioe.ac.uk/shared/get-file.ashx?id=369\&itemtype= document]. (accessed 09.02.17)

37. BMI classification [http://www.who.int/topics/obesity/en/]. Accessed 10 Sept 2018

38. Waist circumference and waist-hip ratio: report of a WHO expert consultation [http://whqlibdoc.who.int/publications/2011/9789241501491 eng.pdf.]. (accessed 10.11.16)

39. What qualification levels mean [https://www.gov.uk/what-different-qualificationlevels-mean]. Accessed 10 Aug 2018.

40. Butler NR, Bonham DG. Perinatal mortality. Edinburgh: livingstone; 1963.

41. Maddock J, Geoffroy MC, Power C, Hypponen E. 25-Hydroxyvitamin D and cognitive performance in mid-life. Br J Nutr. 2014;111(5):904-14.

42. Jokela M, Hamer M, Singh-Manoux A, Batty GD, Kivimaki M. Association of metabolically healthy obesity with depressive symptoms: pooled analysis of eight studies. Mol Psychiatry. 2014;19(8):910-4.

43. Johnston $E$, Johnson $S$, McLeod $P$, Johnston $M$. The relation of body mass index to depressive symptoms. Can J Public Health. 2004;95(3): 179-83.

44. Yu NW, Chen CY, Liu CY, Chau YL, Chang CM. Association of Body Mass Index and Depressive Symptoms in a chinese community population: Results from the Health Promotion Knowldge, Attitude, and Performance Survey in Taiwan. Chang Gung Med J. 2011;34:7. 
45. Simon GE, Arterburn D, Rohde P, Ludman EJ, Linde JA, Operskalski BH, Jeffery RW. Obesity, depression, and health services costs among middleaged women. J Gen Intern Med. 2011;26(11):1284-90.

46. Carslake D, Davey Smith G, Gunnell D, Davies N, Nilsen TIL, Romundstad P. Confounding by ill health in the observed association between BMI and mortality: evidence from the HUNT study using offspring BMl as an instrument. Int J Epidemiol. 2018;47(3):760-70.

47. Hunger JM, Major B. Weight stigma mediates the association between BMI and self-reported health. Health Psychology. 2015;34(2):172-5.

48. Bornstein SR, Schuppenies A, Wong ML, Licinio J. Approaching the shared biology of obesity and depression: the stress axis as the locus of geneenvironment interactions. Mol Psychiatry. 2006;11(10):892-902.

49. Lee JH, Park SK, Ryoo JH, Oh CM, Mansur RB, Alfonsi JE, Cha DS, Lee Y, McIntyre RS, Jung JY. The association between insulin resistance and depression in the Korean general population. J Affect Disord. 2017:208:553-9.

50. Lu XY, Kim CS, Frazer A, Zhang W. Leptin: a potential novel antidepressant. Proc Natl Acad Sci U S A. 2006;103(5):1593-8.

51. Varghese FP, Brown ES. The hypothalamic-pituitary-adrenal Axis in major depressive disorder: a brief primer for primary care physicians. Prim Care Companion J Clin Psychiatry. 2001;3(4):151-5.

52. Kleinridders A, Cai W, Cappellucci L, Ghazarian A, Collins WR, Vienberg SG, Pothos EN, Kahn CR. Insulin resistance in brain alters dopamine turnover and causes behavioral disorders. Proc Natl Acad Sci U S A. 2015;112(11):3463-8.

53. Westphal SA. Obesity, abdominal obesity, and insulin resistance. Clin Cornerstone. 2008:9(1):23-9 discussion 30-21.

54. De Mello MT, Lemos Vde A, Antunes HK, Bittencourt L, Santos-Silva R, Tufik S. Relationship between physical activity and depression and anxiety symptoms: a population study. J Affect Disord. 2013;149(1-3):241-6.

55. Lee O, Lee DC, Lee S, Kim YS. Associations between physical activity and obesity defined by waist-to-height ratio and body mass index in the Korean population. PLoS One. 2016;11(7):e0158245.

56. Golubic R, Wijndaele K, Sharp SJ, Simmons RK, Griffin SJ, Wareham NJ, Ekelund U, Brage S. Physical activity, sedentary time and gain in overall and central body fat: 7-year follow-up of the ProActive trial cohort. Int J Obes. 2015;39(1):142-8.

57. Patton GC, Coffey C, Posterino M, Carlin JB, Wolfe R, Bowes G. A computerised screening instrument for adolescent depression: population-based validation and application to a two-phase case-control study. Soc Psychiatry Psychiatr Epidemiol. 1999;34(3):166-72.

58. Trainor K, Mallett J, Rushe T. Age related differences in mental health scale scores and depression diagnosis: adult responses to the CIDI-SF and MHI-5. J Affect Disord. 2013;151(2):639-45.

Ready to submit your research? Choose BMC and benefit from:

- fast, convenient online submission

- thorough peer review by experienced researchers in your field

- rapid publication on acceptance

- support for research data, including large and complex data types

- gold Open Access which fosters wider collaboration and increased citations

- maximum visibility for your research: over $100 \mathrm{M}$ website views per year

At $\mathrm{BMC}$, research is always in progress.

Learn more biomedcentral.com/submissions 